undoubted poisonous character. So impressed were the two Departmental Committees appointed in I9r I to investigate the incidence of lead poisoning in the two largest trades concerned with painting--buildings and vehicles respectively-that they recommended that, except for special classes of work of very minor importance, the use of paints containing more than a very small percentage of lead compounds soluble in dilute acid should be prohibited.

During the War much experience was gained with many materials, and the mere omission to repaint so many buildings and other structures enabled much valuable information to be gained. In I92I the Home Office found that the information collected in view of the consideration of the use of lead paints by the International Labour Organisation of the League of Nations, was not in the main in accord with the findings of the I9I I committees. Another Departmental Committee, with Sir Henry Norman as chairman, has therefore reviewed the whole question and come to rather different and, it may be said, more reasonable conclusions.

The Committee is satisfied that the specific illnesses of the paint trade are due to lead poisoning and not, as Sir Kenneth Goadby and Prof. H. E. Armstrong were inclined to maintain, to the fumes of turpentine or other hydrocarbon solvents. There certainly appears to be little evidence of chronic disease due to these substances when used apart from lead. The Committee considers it to be generally admitted that dust from the sand-papering of old or new paint-work is almost the only cause of lead poisoning. The introduction of a waterproof sand-paper and the prohibition of dry rubbing-down bids fair to remove this main cause, and rules as to cleanliness simple enough to be enforceable may dispel minor causes.

Sir Frank Baines, of H.M.'s Office of Works, was emphatic as to the superiority of white-lead paint over any substitute for outdoor painting of buildings. Analyses of scrapings from various public buildings confirmed the view that zinc oxide coatings had almost disappeared, exposing the old lead paint beneath. On the other hand, it must be pointed out that leadless paints seem to have given satisfaction when used on vehicles.

Great Britain is pledged to bring in legislation to give effect to the decisions of the Labour Organisation of the League of Nations, and the Committee has prepared draft regulations accepted by both sides of the Joint Industrial Council. It seems doubtful, in view of much of the evidence, whether the prohibition of white lead in internal painting should be strictly enforced, but on the whole, the regulations are salutary and should reduce the number of cases of lead poisoning, while a system of medical inspection should prevent mild cases from becoming chronic.

Lord Askwith in the Times of April 4 points out certain international aspects of the question, and expresses the hope, partly on economic grounds, in view of the possibility of minimising danger from white lead, that prohibition of its use for internal painting in 1927 may not be enforced.

\title{
The Duddell Memorial of the Physical Society.
}

I N October I920 the council of the Physical Society of London decided that Mr. W. du B. Duddell's memory should be perpetuated, and invited the council of the Institution of Electrical Engineers and the council of the Röntgen Society to join in forming a committee to collect funds for the Duddell memorial. The following were the members of the Memorial Committee so formed : Sir William Bragg, Sir Horace Darwin, Sir R. T. Glazebrook, Dr. R. Knox, Prof. T. Mather, Mr. Roger T. Smith, and Mr. RobertS.Whipple. A gratifying response was made to the appeal, nearly 7 ool. being subscribed.

The council of the Physical Society, feeling that Duddell's name will always be associated with the development of scientific instruments, has decided

that the memorial shall take the form of a bronze medal to be awarded periodically to those who have advanced knowledge by the invention or design of scientific instruments or of the materials or methods used in their construction. The interest on $400 l$. (invested in 5 per cent. inscribed stock) will be given to the recipients of the medal.

At a meeting of the Physical Society held on Friday, May II, Sir William Bragg as chairman of the Memorial Committee handed to Dr. Alexander
Russell, the president of the Society, the dies for the medal and the scrip for the investment. Sir Richard Glazebrook, speaking also on behalf of the subscribers to the Memorial Fund, dwelt on Duddell's ability and labour.

Dr. Russell, in accepting the dies, etc., on behalf of the Society, expressed his pleasure that Duddell's work, and especially his work in connexion with the

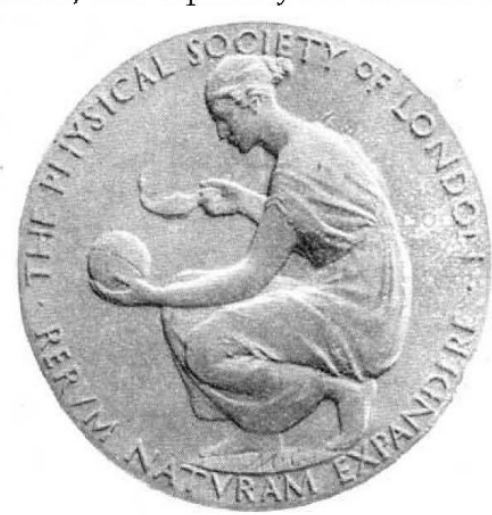
Society, should be perpetuated by a memorial of this kind.

$1 \Leftrightarrow$ The medal (Fig. I), which is in bronze, was designed by Mrs. Mary G. Gillick. The obverse shows the head of Duddell in profile, with his name" William Du Bois Duddell" written above it. The dates of his birth and death - I872 and I9I7 -are placed in Roman characters horizontally across the medal. The artist has succeeded in showing in a striking manner the alert energy of Duddell as well as the erectness of his carriage. The reverse represents the quest of science for knowledge, a symbolic figure, throwing light on the mysteries of the earth. Above the figure the words "The Physical Society of London "appear, while below is the motto "Rerum naturam expandere," which may be freely translated, "To elucidate the causes of things." 